\title{
Selective Detection of Peptide-Oligonucleotide Heteroconjugates Utilizing Capillary HPLC-ICPMS
}

\author{
Brittany Catron, ${ }^{1,2}$ Joseph A. Caruso, ${ }^{1}$ Patrick A. Limbach ${ }^{2}$ \\ ${ }^{1}$ University of Cincinnati/Agilent Technologies Metallomics Center of the Americas, Department of Chemistry, University of \\ Cincinnati, Cincinnati, OH 45221-0172, USA \\ ${ }^{2}$ Rieveschl Laboratories for Mass Spectrometry, Department of Chemistry, University of Cincinnati, P.O. Box 210172, \\ Cincinnati, OH 45221-0172, USA
}

\begin{abstract}
A method for the selective detection and quantification of peptide:oligonucleotide heteroconjugates, such as those generated by protein:nucleic acid cross-links, using capillary reversedphase high performance liquid chromatography (cap-RPHPLC) coupled with inductively coupled plasma mass spectrometry detection (ICPMS) is described. The selective detection of phosphorus as ${ }^{31} \mathrm{P}^{+}$, the only natural isotope, in peptide-oligonucleotide heteroconjugates is enabled by the elemental detection capabilities of the ICPMS. Mobile phase conditions that allow separation of heteroconjugates while maintaining ICPMS compatibility were investigated. We found that trifluoroacetic acid (TFA) mobile phases, used in conventional peptide separations, and hexafluoroisopropanol/triethylamine (HFIP/TEA) mobile phases, used in conventional oligonucleotide separations, both are compatible with ICPMS and enable heteroconjugate separation. The TFA-based separations yielded limits of detection (LOD) of $\sim 40 \mathrm{ppb}$ phosphorus, which is nearly seven times lower than the LOD for HFIP/TEA-based separations. Using the TFA mobile phase, $1-2$ pmol of a model heteroconjugate were routinely separated and detected by this optimized capLC-ICPMS method.
\end{abstract}

Key words: Inductively coupled plasma mass spectrometry, Protein-nucleic acid cross-links, Elemental phosphorus detection, Liquid chromatography-mass spectrometry, Quantitative analysis

\section{Introduction}

$\mathrm{P}$ rotein:nucleic acid complexes are critical for cell survival and are involved in various cell functions including DNA replication, packaging, repair, and transcription as well as RNA maturation, transport, and translation [1-6]. Chemical and photochemical cross-linking has proven to be a useful approach for covalently linking proteins with nucleic acids to impose distance constraints on such complexes [7-13]. These constraints, when combined with data from biophysical techniques such as X-ray crystallography, nuclear magnetic resonance (NMR), and cryoelectron microscopy, allow researchers to develop more accurate three-dimensional structures, thereby improving our understanding of these biologically significant complexes [14-17].

Correspondence to: Patrick A. Limbach; e-mail: Pat.Limbach@uc.edu
While a number of biophysical approaches have been used for characterizing protein:nucleic acid cross-links, one of the more promising instrumental methods is the use of mass spectrometry (MS) $[12,18]$. The potential advantages of MS for the analysis of cross-links include its ability to analyze high molecular weight complexes either intact or through analysis of enzymatic digestion products, the relatively high sensitivity of MS for peptides and oligonucleotides, and the compatibility of this method with a variety of different cross-linking reagents [8, 12, 19].

Although MS methods are especially useful in identifying the proteins involved in protein:nucleic acid complexes, identifying the specific sites of cross-linking within these complexes is not trivial because of the low abundance of cross-linked species and the high background of non-crosslinked components [20]. A large number of analytical developments to improve the sensitivity and reliability of 
cross-link detection have been pursued, primarily by Urlaub and co-workers [8,11, 13, 21-23], along with some work by our group [24-26]. Urlaub and co-workers have utilized Edman degradation combined with matrix-assisted laser desorption/ionization mass spectrometry (MALDI-MS) [7, 27] or alkaline phosphatase treatment with MALDI-MS [22] to identify cross-linking sites on the protein component of the protein:nucleic acid complex. Reversed-phase high performance liquid chromatography electrospray ionization mass spectrometry (RP-HPLC-ESI-MS) methods that have been explored include the use of multiple reaction monitoring (MRM) scans designed to identify the loss of a metaphosphoric acid group $\left(\mathrm{HPO}_{3},-80 \mathrm{Da}\right)$, which serves as a signature for peptide:oligonucleotide cross-links present in a mixture of peptides [23], or LC-ESI-MS-based scans utilizing the unique mass defect of peptide:oligonucleotide cross-links to differentiate between peptides and cross-links [25]. Most recently, the use of electron-induced dissociation methods for complete sequencing of electrosprayed peptide: oligonucleotide heteroconjugates was presented [26].

While MALDI- and ESI-MS approaches have been used extensively for characterizing peptide:oligonucleotide heteroconjugates and protein:nucleic acid cross-links, to our knowledge, there have been no prior investigations into the use of inductively coupled plasma mass spectrometry (ICPMS) for such analyses. This discovery was surprising as ICPMS is a powerful analytical tool for element-specific analysis, as the signal response is directly proportional to the element concentration in the sample and this ionization source is not matrix or sequence dependent $[28,29]$.

Recent ICPMS developments allow for the detection of previously intractable elements such as phosphorus. Quantitation of post-translationally modified proteins (phosphoproteins and sulfated proteins) by phosphorus or sulfur monitoring during LC-ICPMS analysis of proteolytic digests is now commonly performed [28-31]. Similarly, LC-ICPMS monitoring of phosphorus or sulfur can also be used for the identification and quantification of oligodeoxynucleotides and phosphorothioate oligonucleotides [32, 33].

Here we have examined the applicability of LC-ICPMS for identifying and characterizing peptide:oligonucleotide heteroconjugates. This work is based on the premise that such heteroconjugates can be selectively detected by monitoring for elemental phosphorus, which is present in the heteroconjugate from the phosphodiester linkage of the oligonucleotide, using ICPMS. If possible on these heteroconjugates, this instrumental approach could then enable the selective detection and quantification of protein:nucleic acid cross-links. Before pursuing such cross-links, these initial studies have focused on the appropriate chromatographic and instrumental conditions required to detect phosphorus arising from the oligonucleotide component of the heteroconjugate, and to identify the analytical figures of merit for quantitative analysis of phosphorus from such heteroconjugates. Multiple chromatographic conditions were investigated, and a suitable analytical method for characterizing heteroconjugates is demonstrated using a model peptide: oligonucleotide construct.

\section{Materials and Methods}

\section{Materials}

HPLC/Spectro grade acetonitrile and methanol $(\mathrm{MeOH})$ were purchased from Tedia (Fairfield, OH, USA). HPLC grade triethylamine (TEA), trifluoroacetic acid (TFA), urea, and ammonium bicarbonate were from Fisher Scientific (Fairlawn, NJ, USA). Bovine serum albumin (BSA), 1,1,1,3,3,3 hexafluoro-2-propanol (HFIP), neurotensin, bradykinin, Substance $\mathrm{P}$ fragment 2-11, adrenocorticotropic hormone $(\mathrm{ACTH})$, dithiothreitol, iodoacetamide, and $\mathrm{dT}_{10}$ were obtained from Sigma-Aldrich (St. Louis, MO, USA). RNase T1 (Roche Molecular Biochemicals, Indianapolis, IN, USA) was purified and used as described previously [34]. Sequence grade modified trypsin was purchased from Promega (Madison, WI, USA) and used per the manufacturer's instructions. Pp60c-src was from American Peptide Company (Sunnyvale, CA, USA). The model heteroconjugate was an 11-amino acid reside peptide conjugated to a 5mer oligonucleotide via a hexylaminolinker on the aspartic residue (Ac-GARGAD(agcca)RAVLA- $\mathrm{NH}_{2}$ ) obtained from BiomerTech (Hayward, CA, USA) [25].

\section{HPLC}

HPLC was carried out on an Agilent 1200 series system (Santa Clara, CA, USA) equipped with a vacuum degasser, binary pump, a thermostatically controlled well plate autosampler, a thermostatically controlled column compartment, a diode array detector, and a $500 \mathrm{~nL}$ flow cell. All lines within the capillary system were $50 \mu \mathrm{m}$ i.d. PEEK fused silica tubing. An Agilent Zorbax 300 Extend $\mathrm{C}_{18}$ capillary column $(0.3 \times 100 \mathrm{~mm})$ with a pore size of $300 \AA$ and $3.5 \mu \mathrm{m}$ particles was used.

The TFA-based mobile phase consisted of mobile phase A of water with $0.05 \%$ TFA and mobile phase B of $0.045 \%$ TFA in acetonitrile. Gradient conditions, at a flow rate of $10 \mu \mathrm{L} \mathrm{min}{ }^{-1}$, including column equilibration, were $5 \mathrm{~min}$ at $0 \% \mathrm{~B}$ followed by a linear ramp to $60 \% \mathrm{~B}$ at $55 \mathrm{~min}$. The gradient was held at $60 \% \mathrm{~B}$ for $5 \mathrm{~min}$ before ramping to $100 \% \mathrm{~B}$ in $5 \mathrm{~min}$. After holding at $100 \%$ B for $5 \mathrm{~min}$, the gradient was linearly decreased to $0 \% \mathrm{~B}$ in $5 \mathrm{~min}$ and held there for $20 \mathrm{~min}$ in preparation for the next run.

The HFIP/TEA mobile phase consisted of mobile phase A composed of $150 \mathrm{mM}$ HFIP and $4 \mathrm{mM}$ TEA in water, while mobile phase B was $150 \mathrm{mM}$ HFIP and $4 \mathrm{mM}$ TEA in methanol. Gradient conditions at a flow rate of $8 \mu \mathrm{L} \mathrm{min}{ }^{-1}$ and column temperature of $50{ }^{\circ} \mathrm{C}$ were a linear ramp from $0 \% \mathrm{~B}$ to $10 \% \mathrm{~B}$ in 2 min followed by a ramp to $20 \% \mathrm{~B}$ in 13 min. After holding at $20 \%$ B for $5 \mathrm{~min}$, the gradient was ramped to $60 \% \mathrm{~B}$ in $5 \mathrm{~min}$ and then $100 \% \mathrm{~B}$ in $5 \mathrm{~min}$. The 
gradient was held at $100 \% \mathrm{~B}$ for $10 \mathrm{~min}$ before decreasing to $0 \% \mathrm{~B}$ in $5 \mathrm{~min}$. The gradient was held at $0 \% \mathrm{~B}$ for $20 \mathrm{~min}$ in preparation for the next run.

\section{Inductively Coupled Plasma Mass Spectrometer}

ICPMS experiments were conducted on an Agilent 7700x ICPMS (Agilent Technologies, Santa Clara, CA), equipped with an octopole reaction system (ORS), which is composed of an on-axis rf-only octopole that produces a tight ion beam. The ICPMS included a shield torch, an octopole cell with pressurized helium gas (purity of $99.999 \%$ ), a quadrupole mass analyzer and an electron multiplier. Interference removal is accomplished by the ORS through kinetic energy discrimination. The polyatomic spectral interferences are eliminated when pressurized gas fills the cell and collides or reacts with such molecules resulting in a loss of kinetic energy. The sample eluting from the HPLC was introduced into the plasma at a flow rate of $8-10 \mu \mathrm{L} \mathrm{min}{ }^{-1}$ through a DS-5 micro-concentric nebulizer (MCN) purchased from CETAC Technologies (Omaha, NE, USA). Phosphorus was monitored at $m / z$ 31. Instrumental parameters used were RF forward power, 1550, plasma Ar gas flow rate, $15.0 \mathrm{~L} \mathrm{~min}^{-1}$, carrier Ar gas flow rate, $1.10 \mathrm{~L} \mathrm{~min}^{-1}$, and helium gas flow rate, $4.0 \mathrm{ml} \mathrm{min}$. The resulting data were analyzed using Agilent MassHunter ICPMS software.

\section{Results and Discussion}

The use of RP-HPLC-ICPMS for the detection of peptide: oligonucleotide heteroconjugates is quite distinct from MALDI- or ESI-MS approaches. ICPMS enables elementspecific detection (e.g., phosphorus and/or sulfur), minimal matrix interferences, and quantitative analysis as the element response is directly proportional to the total mass of that element in the sample. In developing an LC-based ICPMS method for covalently linked heteroconjugate detection, the RP-HPLC conditions required to adequately retain a heteroconjugate within a complex sample that are compatible with the ICP source must be identified.

There are specific concerns that can arise when LC methods are coupled to ICPMS. As the ionization step in ICPMS first requires vaporization and atomization of the sample solution, the use of high amounts of organic solvents can lead to plasma instability and carbon deposition on the interface cones. Because the separation of biomolecules, such as peptides and oligonucleotides, using RP-HPLC typically requires high concentrations of organic solvent or buffer to elute the sample from the column, care must be taken to reduce the overall volume of LC eluent introduced into the ICP source. Thus, we first examined both peptidebased RP-HPLC conditions, where TFA is present in the mobile phase, and conventional oligonucleotide ion-pairing RP-HPLC conditions, where HFIP and TEA are the major components of the mobile phase, using cap-LC to ensure that the mobile phase conditions amenable to ICP-MS [31, 32] would adequately separate the biomolecules of interest. The acidic mobile phases and solution conditions investigated have been utilized previously with heteroconjugates, such as that used here as a model system, and were not found to affect the integrity of the heteroconjugate $[13,21,25,26]$.

\section{HPLC Retention Characteristics}

Initial investigations into the ability of various HPLC mobile phases to separate and retain a mixture of peptides and oligonucleotides in the same sample were performed using diode array, rather than ICPMS, detection. A TFA-based mobile phase and $\mathrm{C} 18$ stationary phase were used as typical peptide-like HPLC conditions. To initially investigate these conditions, several standard peptides including bradykinin, ACTH and neurotensin, along with a tryptic digest of bovine serum albumin and an oligodeoxynucleotide $\left(\mathrm{dT}_{10}\right)$ were used as representative samples. Not surprisingly, under these HPLC conditions, all of the peptides investigated could be retained on the column while the oligodeoxynucleotide eluted in the void volume (data not shown). Similarly, when these same samples were analyzed using HPLC mobile phases typically used for oligonucleotide separation, only the oligodeoxynucleotide was significantly retained on the same C18 column (data not shown).

Consistent with previous results from LC-ESI-MS [25], the nature of the heteroconjugate will dictate the optimal chromatographic conditions. A heteroconjugate that is more "peptide-like," that is, one where the peptide component is large and the oligonucleotide component is small, is best analyzed using conventional peptide-like HPLC conditions such as TFA. Peptide-like heteroconjugates should be retained on the stationary phase effectively under these conditions. Conversely, a heteroconjugate that is more "oligonucleotide-like," that is one where the oligonucleotide component is large and the peptide component is small, is best analyzed using oligonucleotide HPLC conditions.

\section{Phosphorus Detection and Matrix Effects}

While the initial investigations into HPLC conditions were conducted to verify the applicability of such conditions for samples containing peptide- and oligonucleotide-like components, detection was performed using UV spectroscopy. The next series of experiments focused on the applicability of these mobile phases using ICPMS for element-specific detection of heteroconjugates. Here, phosphorus was chosen as the element to be monitored at $m / z \quad 31\left({ }^{31} \mathrm{P}^{+}\right)$for heteroconjugate detection. Phosphorus is present from the oligonucleotide component of the heteroconjugate and, except when phosphopeptides are present, background interferences are expected to be minimal, provided the ORS is used. LC-ICPMS conditions were first optimized using Pp60, a phosphorylated peptide, as the model compound for peptide-like HPLC conditions and $\mathrm{dT}_{10}$ as the model compound for oligonucleotide-like HPLC conditions, after which the 
effects of background non-phosphorus-containing species on the identification of these model compounds was pursued.

A tryptic digest of BSA was chosen as a representative sample matrix to examine whether a background of nonphosphorylated peptides would interfere with the detection of phosphorus-containing samples, such as a heteroconjugate, during ICPMS analysis. The interest here was to identify whether heteroconjugates would need to be purified extensively from uncross-linked protein samples prior to LC-ICPMS. BSA does not contain any sites of phosphorylation, and there was no ICPMS signal from ${ }^{31} \mathrm{P}^{+}$detected when running a tryptic digest of BSA as a control (data not shown). Using TFA mobile phase conditions, Pp60 was spiked into a tryptic digest of BSA, and detected using ICPMS. As shown in Figure 1a, the ${ }^{31} \mathrm{P}$ chromatogram of the ICPMS gives rise to only the phosphorus signal attributable to the Pp60, eluting at $25 \mathrm{~min}$. By way of
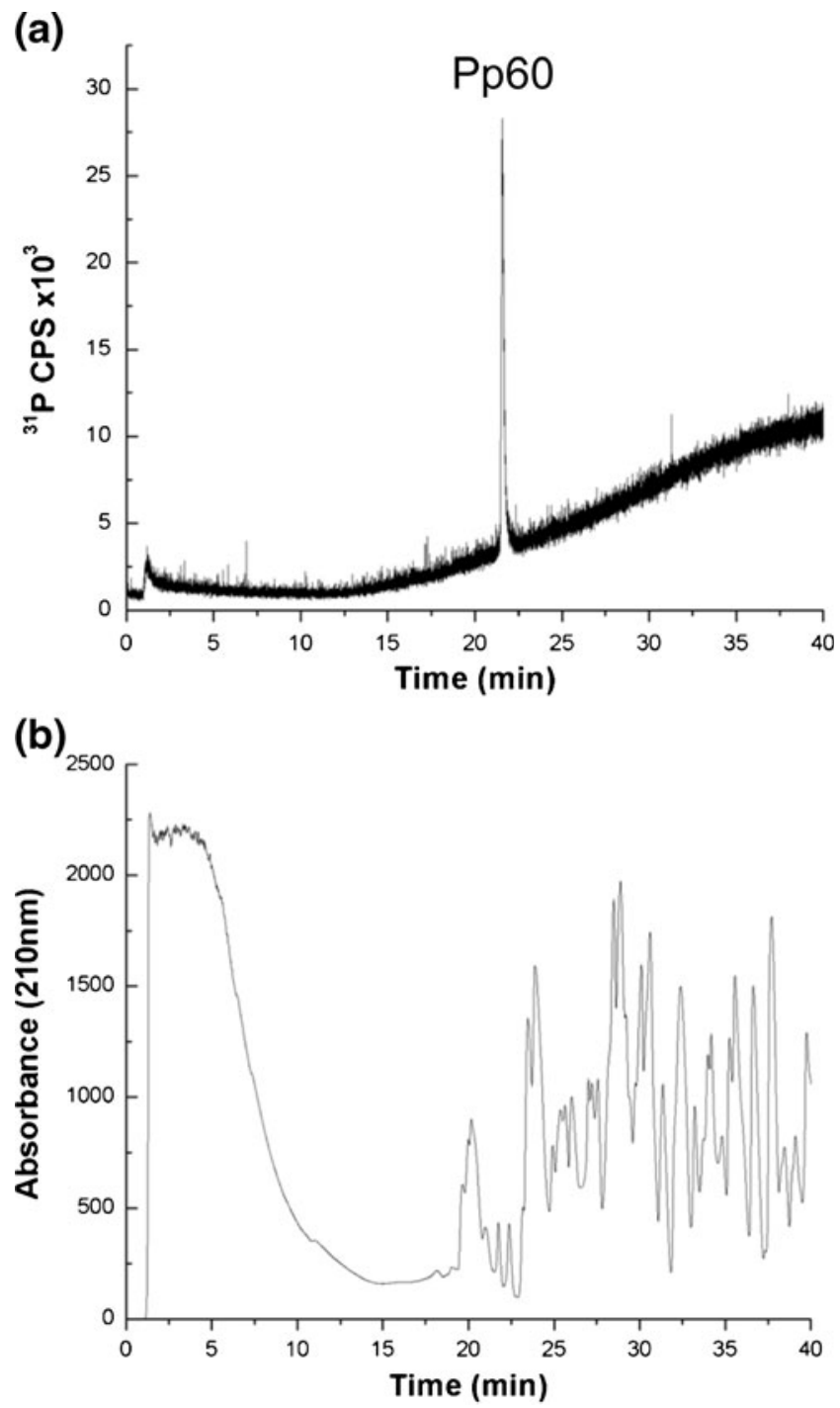

Figure 1. Separation of Pp60 and digested BSA using TFAbased mobile phase conditions. (a) Pp60 detected by monitoring $\mathrm{m} / \mathrm{z} 31\left(\mathrm{P}^{+}\right)$, (b) UV absorbance at $210 \mathrm{~nm}$ comparison, the UV chromatogram (detection at $210 \mathrm{~nm}$ ) of the same run (Figure 1b) reveals numerous eluting peaks arising from the tryptic peptides from BSA as well as the spiked Pp60.

Additional experiments were performed where the amount of Pp60 injected on column was held constant at 32.2 pmol, while the amount of the BSA tryptic digest was varied from 7.2 to 21 pmol of tryptic digest loaded on column. As shown in Table 1, the addition of the tryptic digest of BSA as a background had a negligible effect on the phosphorus response from Pp60 with a deviation of $<10 \%$ for all amounts of the BSA digest investigated. Thus, we conclude that the use of the TFA-based mobile phase during LC-ICPMS enables the element-specific detection of phosphorus in the presence of a non-phosphorus-containing peptide background. Although the sample to matrix ratio investigated here is likely higher than what may be expected from isolation of cross-links from biological systems [13], these findings are consistent with other ICPMS results from a similar instrument for low abundance phosphopeptide detection [31].

In a similar manner, LC-ICPMS with phosphorus-specific detection was investigated using HFIP/TEA mobile phase conditions. $\mathrm{dT}_{10}$ was spiked into a tryptic digest of BSA and detected using ICPMS. As shown in Figure 2a, the phosphorus chromatogram from the ICPMS only reveals the phosphorus signal attributable to $\mathrm{dT}_{10}$, which elutes at $12 \mathrm{~min}$. However, the UV chromatogram with detection at $210 \mathrm{~nm}$ (Figure $2 \mathrm{~b}$ ) of the same run reveals a large background signal in the first $5 \mathrm{~min}$, presumably attributable to unretained or slightly retained peptides, and only a few discernable peaks in the chromatogram after $10 \mathrm{~min}$. These experiments confirm that LC-ICPMS can be used to selectively detect phosphorus (from $\mathrm{dT}_{10}$ ) even in a sample matrix composed of numerous other peptides.

Next, the effect of sample-related matrix effects were investigated using the HFIP/TEA mobile phase. The amount of $\mathrm{dT}_{10}$ loaded on column was held constant at $3.6 \mathrm{pmol}$, and a variable amount of tryptic peptides from BSA ranging from 7.2 to $21 \mathrm{pmol}$ were also loaded on column. As seen in Table 1, the addition of tryptic peptides as a background for $\mathrm{dT}_{10}$ detection had a minimal effect, with a deviation of $<4 \%$ for the phosphorus signal. Thus, we conclude that the use of HFIP/TEA as a mobile phase during LC-ICPMS enables the element-specific detection of phosphorus irrespective of the

Table 1. Effect of Peptide Background, from Tryptic Digest of BSA, on Measured Phosphorus Response for Pp60 in TFA Mobile Phase Conditions and $\mathrm{dT}_{10}$ in HFIP/TEA Mobile Phase Conditions

\begin{tabular}{lcc}
\hline BSA (pmol) & Pp60 Area $(\mathrm{cps})$ & $\mathrm{dT}_{10}$ Area $(\mathrm{cps})$ \\
\hline 21 & 16153 & 5239 \\
14 & 16916 & 5474 \\
10 & 19040 & 5595 \\
8.5 & 17573 & 5363 \\
7.2 & 20516 & 5467 \\
\%RSD & 9.7 & 3.7 \\
\hline
\end{tabular}



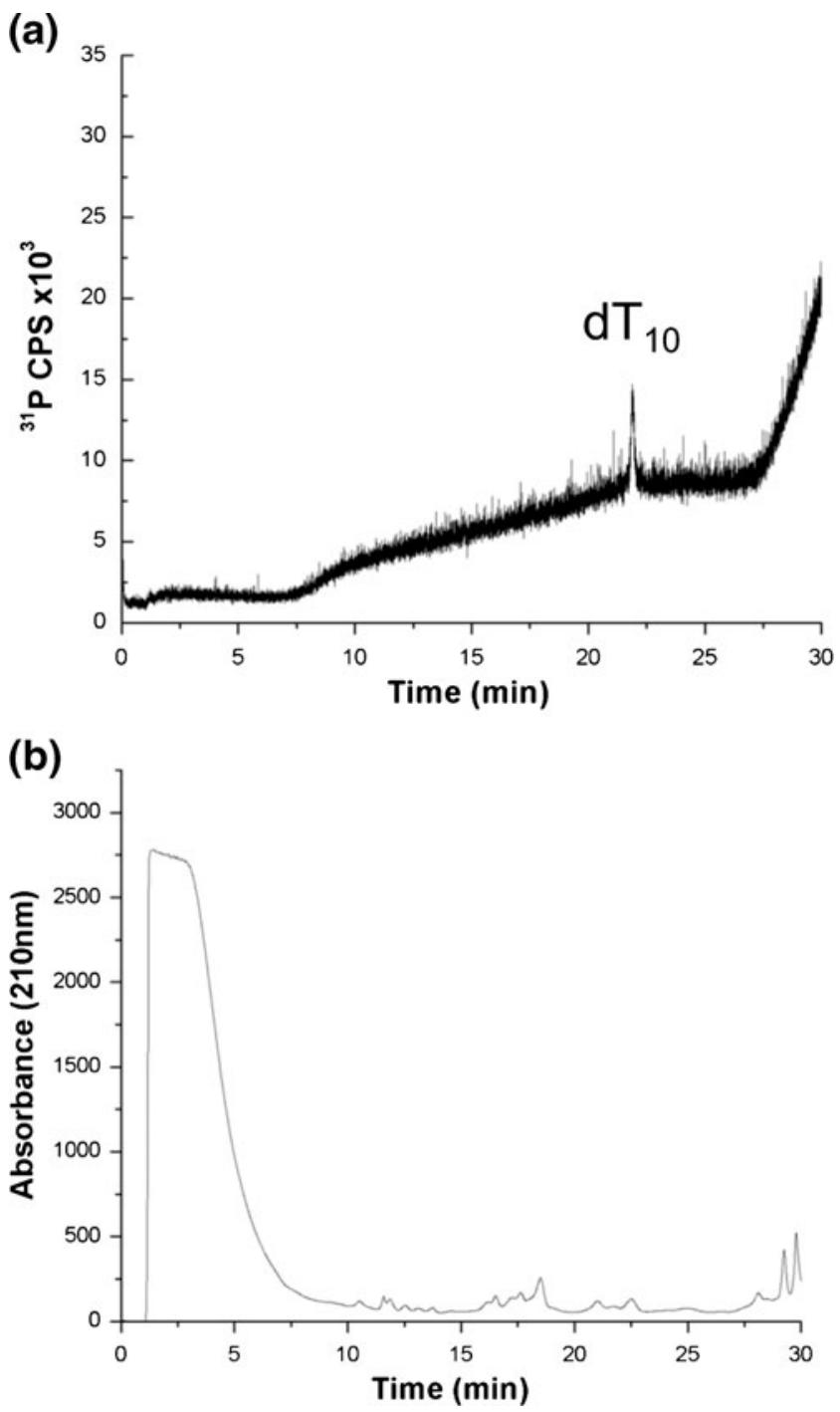

Figure 2. Separation of $\mathrm{dT}_{10}$ and digested BSA using HFIP/ TEA mobile phase conditions. (a) $\mathrm{dT}_{10}$ detected by monitoring $\mathrm{m} / \mathrm{z} 31\left(\mathrm{P}^{+}\right)$, (b) UV absorbance at $210 \mathrm{~nm}$

amount of non-phosphorus-containing peptide background. Taken together, neither mobile phase conditions seemed adversely affected by sample matrix effects allowing either to be used for the LC-ICPMS detection of phosphorus from peptide:oligonucleotide heteroconjugates.

\section{Quantitative Analysis of Phosphorus by HPLC-ICPMS}

The final evaluation of HPLC-ICPMS conditions for heteroconjugate characterization focused on the quantitative measurement of phosphorus within the sample. The same standards for the TFA and HFIP/TEA mobile phases as before were used for these investigations. The experimental procedure involved using known amounts of Pp60 or $\mathrm{dT}_{10}$ loaded on column and measuring the ICPMS response for phosphorus. Response curves were generated from peak area measurements of phosphorus from which the limits of detection (LOD) and quantification (LOQ) for phosphorus could be determined. The LODs and LOQs were calculated using IUPAC-based calculations of $3 \sigma$ and $10 \sigma$, respectively, where $\sigma$ is the calculated standard deviation of the measurements [35].

Response curves for Pp60 analyzed using the TFA mobile phase and $\mathrm{dT}_{10}$ analyzed using the HFIP/TEA mobile phase were generated (data not shown). Using the TFA mobile phase, the LOD determined for the amount of phosphorus signal is $41 \mathrm{ppb} \mathrm{P}$, which correlates to $1.3 \mathrm{pmol}$ Pp60 loaded on column, and a corresponding LOQ of $137 \mathrm{ppb} \mathrm{P}$ equivalent to 4.4 pmol Pp60 loaded on column. Using the HFIP/TEA mobile phase, the LOD determined for the amount of phosphorus was $280 \mathrm{ppb}$, which corresponds to $1.0 \mathrm{pmol}$ of $\mathrm{dT}_{10}$ loaded on column, and a corresponding LOQ of $936 \mathrm{ppb} \mathrm{P}$ equivalent to $3.4 \mathrm{pmol}$ of $\mathrm{dT}_{10}$ loaded on column. These data show that the TFA mobile phase yields lower LODs and LOQs for phosphorus than the HFIP/TEA mobile phase, which may arise from effects in the source region due to the differences in the mobile phase compositions. Because $\mathrm{dT}_{10}$ contains nine phosphorus atoms per molecule, the amount of sample required to load on column is reduced, thus explaining why the sample loading was equivalent between Pp60 and $\mathrm{dT}_{10}$ even though the LOD for phosphorus is lower for the TFA conditions. These results also suggest that a larger oligonucleotide component (i.e., more phosphorus per oligonucleotide component) would be advantageous for ICPMS detection when using the HFIP/ TEA mobile phase conditions. The LOD values obtained here $(\leq \mu \mathrm{mol}$ concentration) are comparable to values previously reported for cross-link or heteroconjugate characterization by LC-ESI-MS [16-21], and additional investigation of alternative nebulization sources may improve these LOD values further [32].

\section{Model Heteroconjugate}

The preceding experiments demonstrated that both TFA and HFIP/TEA conditions are suitable for LC-ICPMS analysis of phosphorus-containing compounds. As expected, TFAbased conditions would be applicable for characterizing heteroconjugates that contain a larger peptide coupled to a smaller oligonucleotide, while HFIP/TEA conditions would be preferred when the heteroconjugate contains a larger oligonucleotide and only one or a few amino acids. As neither mobile phase composition is affected by nonphosphorus-containing background ions and the quantitative capabilities are similar, the optimal set of LC-ICPMS experimental conditions can be dictated by the heteroconjugate of interest, thereby providing significant experimental flexibility for analytical use.

Because the optimization and characterization studies were conducted on simple non-heteroconjugate standards, to confirm that these findings hold for heteroconjugate analysis, the next experiments were performed using the unpurified synthetic reaction mixture of an 11-amino acid residue 
peptide conjugated to a 5-mer oligonucleotide via a hexlyaminolinker on the aspartic residue (Ac-GARGAD (agcca)RAVLA-NH ${ }_{2}$ ) $[25,26]$ as the demonstration system. The reaction mixture was analyzed by LC-ICPMS using TFA (Figure 3a) and HFIP/TEA (Figure 3b) mobile phases with all other experimental conditions equivalent to those used in the initial optimization studies.

As expected, both HPLC conditions were appropriate for retaining the heteroconjugate components, although the chromatographic profiles differ between the two mobile phases used. In Figure 3a, the major peak corresponding to the heteroconjugate elutes near $20 \mathrm{~min}$, followed by several additional later-eluting peaks in the RP ion-pairing chromatogram. These
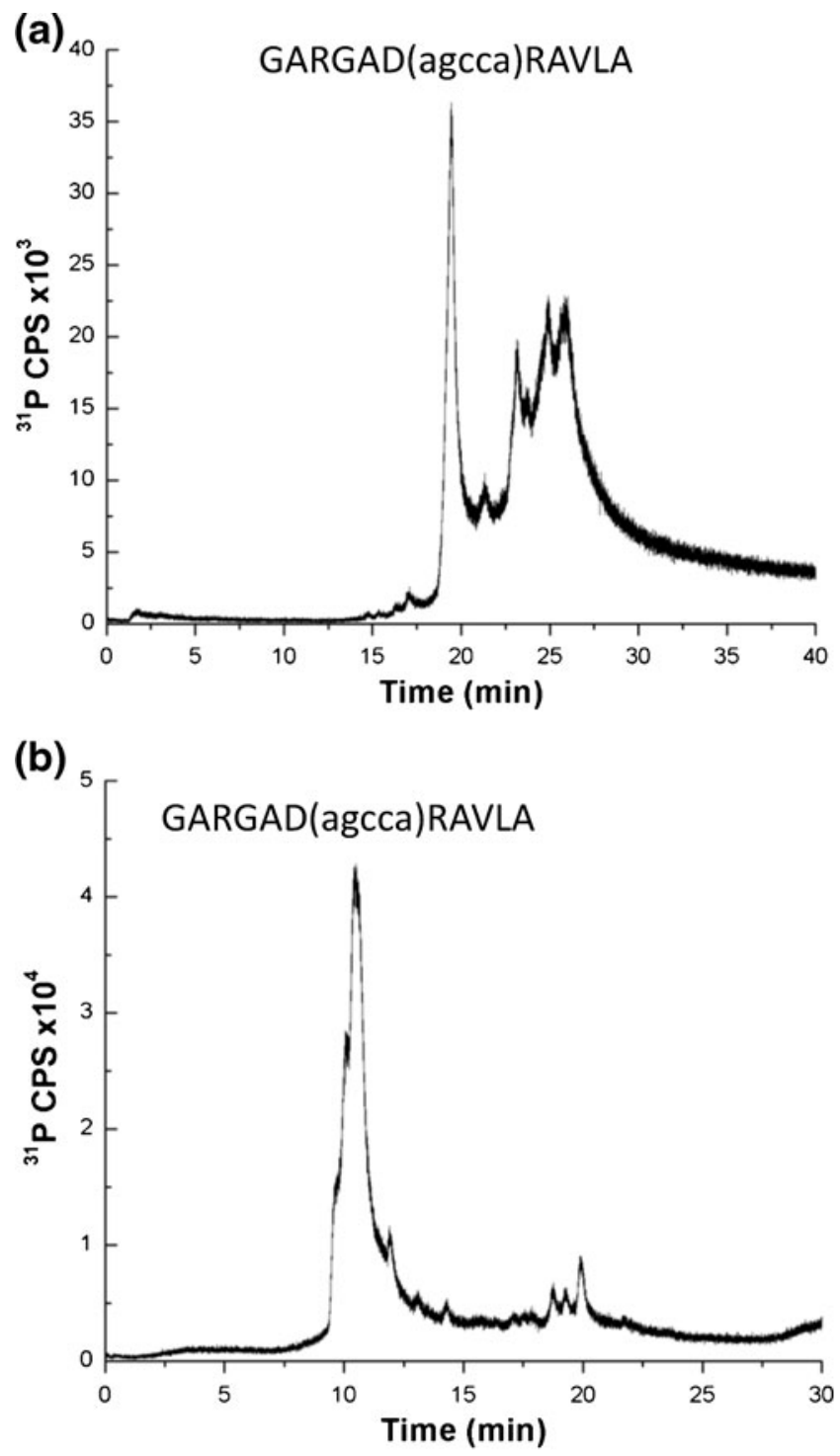

Figure 3. LC-ICPMS analysis of unpurified heteroconjugate (Ac-GARGAD(agcca)RAVLA-NH $\mathrm{NH}_{2}$ with peptide residues in upper case and nucleotide resides in lower case) using (a) TFA and (b) HFIP/TEA mobile phase conditions with detection by monitoring phosphorus at $m / z 31\left(\mathrm{P}^{+}\right)$ additional peaks arise from incomplete deprotection of the peptide, which has previously been shown to yield a similar reversed-phase HPLC during UV detection [25], and thus represent different peptide components, each containing the same oligonucleotide. As the protecting groups increase the hydrophobicity of the peptide, these additional species are detected as later eluting components.

In contrast, using HFIP/TEA conditions, which separate based on the oligonucleotide characteristics of the heteroconjugate, only one major peak is detected eluting around $11 \mathrm{~min}$ (Figure 3b). This peak is not well resolved, with leading shoulders. Unlike the chromatogram obtained using TFA conditions in Figure 3a, here the different peptide components cannot be resolved by the HFIP/TEA mobile phase. The smaller set of peaks eluting around $20 \mathrm{~min}$ may be due to aggregation of the heteroconjugate due to the amount of sample loaded, although these peaks were not investigated further.

Finally, to further examine the influence of oligonucleotide size on peptide-based separations, the heteroconjugate sample was purified as described previously [25], digested with either trypsin or RNase T1, which cleaves oligonucleotides at unmodified guanosine residues, to generate a mixture of analytes where either the peptide or oligonucleotide component differs in length from the purified heteroconjugate. These samples were then analyzed by LC-ICPMS using the TFA mobile phase conditions. Figure $4 \mathrm{a}$ is the ICPMS data obtained when monitoring for phosphorus. As expected for the purified heteroconjugate, only a single peak eluting at $19.6 \mathrm{~min}$ was detected, consistent with the data obtained from the unpurified heteroconjugate sample analyzed in Figure 4a. Integrating the phosphorus signal over this peak area yielded a value of $2331 \mathrm{cps}$, which, based on the response curve for phosphorus under these chromatographic conditions, corresponds to $\sim 175 \mathrm{ppb} \mathrm{P}$ or $\sim 2.2 \mathrm{pmol}$ of heteroconjugate.

Digestion of the heteroconjugate using RNase T1 is predicted to generate two products: the trinucleotide 5'CpApA-3' and the intact peptide now containing a dinucleotide component [(Ac-GARGAD(ag)RAVLA-NH $\mathrm{NH}_{2}$. LCICPMS analysis of the RNase T1 digest of the heteroconjugate is presented in Figure $4 \mathrm{~b}$. The major peak, corresponding to the heteroconjugate now containing a dinucleotide, elutes at $20.4 \mathrm{~min}$, and a small peak elutes at $1.4 \mathrm{~min}$, which is near the void volume for the column. In this case, the new heteroconjugate elutes at a statistically significant later elution time, likely due to the increase in hydrophobicity of this heteroconjugate as the oligonucleotide component has been reduced in size. The additional peak eluting near the void volume is consistent with the trinucleotide that results after RNase T1 digestion. As discussed earlier, the trinucleotide would not be retained under these RP-HPLC conditions due to the polarity of the sample and the lack of ion pairing reagent in the mobile phase. A quantitative characterization of the RNase T1 digest of the heteroconjugate can be done by integrating 
(a)

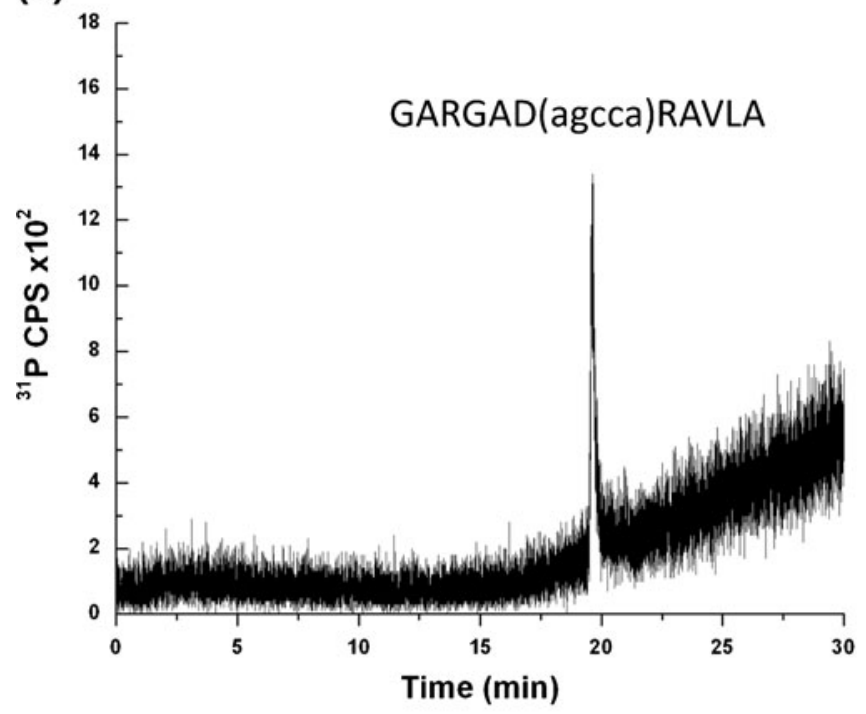

(b)

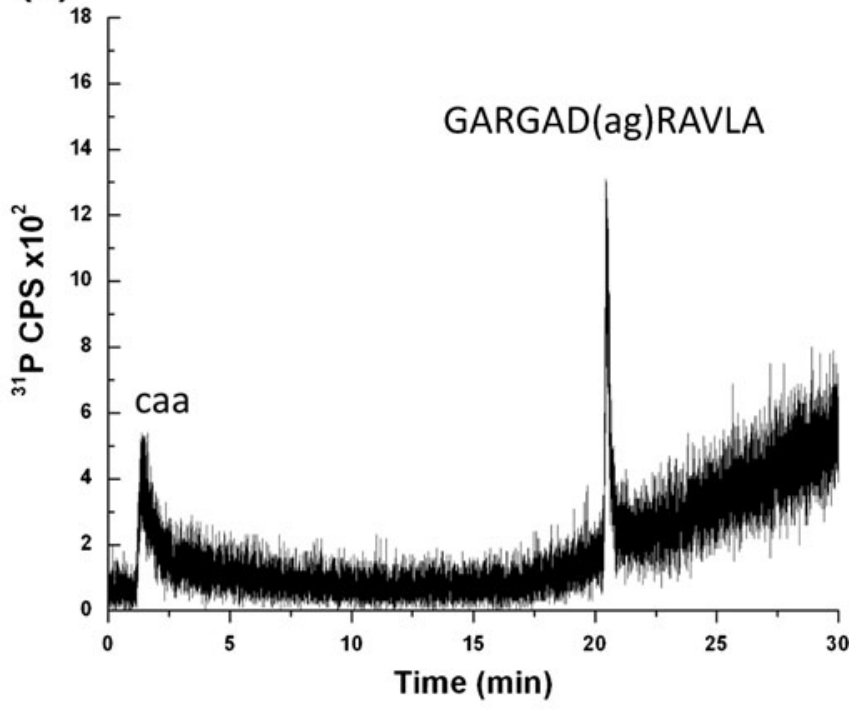

(c)

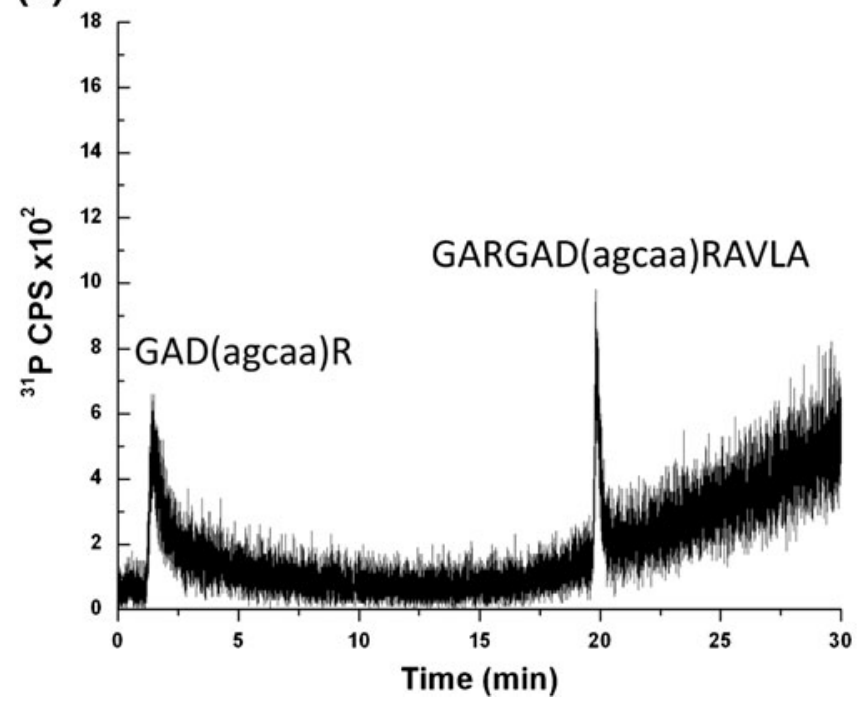

Figure 4. LC-ICPMS analysis using TFA mobile phase conditions with detection by monitoring phosphorus at $m / z 31\left(\mathrm{P}^{+}\right)$. (a) Sample injected is purified heteroconjugate (Ac-GARGAD(agcca)RAVLA-NH $\mathrm{N}_{2}$ with peptide residues in upper case and nucleotide resides in lower case). (b) Sample injected is RNase T1 digest of purified heteroconjugate. (c) Sample injected is tryptic digest of purified heteroconjugate. Approximately 10-fold less purified heteroconjugate was used for these analyses compared to the analyses in Figure 3

both phosphorus peak areas. The phosphorus signal for the trinucleotide eluting at $1.4 \mathrm{~min}$ yielded a value of $1063 \mathrm{cps}$ ( $\sim 80 \mathrm{ppb}$ P), and the heteroconjugate with the dinucleotide remaining attached yielded a value of $1157 \mathrm{cps}(\sim 87 \mathrm{ppb}$ $\mathrm{P}, \sim 1.9 \mathrm{pmol}$ of digested heteroconjugate). Not unexpectedly, given that both peaks containing two phosphorus atoms per oligonucleotide, the detected ICPMS response is approximately equivalent and half that from the intact heteroconjugate.

Digestion of the heteroconjugate with trypsin is predicted to generate a smaller peptide still conjugated to the oligonucleotide component [GAD(agcaa)R] along with two smaller peptides that would not be conjugated to the oligonucleotide (GAR and AVLA), which cannot be detected by the LC-ICPMS method described here. Analysis of the tryptic digest of the heteroconjugate by LC-ICPMS (Figure 4c) yields two peaks. The major peak, eluting at $19.8 \mathrm{~min}$, corresponds to the starting heteroconjugate that was not digested by trypsin. Interestingly, the additional peak also elutes very early in the chromatographic method, $1.4 \mathrm{~min}$, which is near the void volume of the column. Because this method can only detect phosphorus, this early eluting peak is a tryptic peptide that remains conjugated to the oligonucleotide. The identity of this tryptic product cannot be determined by ICPMS analysis, although several possibilities exist: GAD(agcaa)R, GARGAD(agcaa)R, and 
GAD(agcaa)RAVLA. Based on the early retention time for this product using the TFA mobile phase, the most likely product is that with the smallest peptide component [GAD (agcaa)R], although further analysis would be required to confirm that identification.

A possible interpretation for the tryptic peptide-oligonucleotide component eluting so early is that the chromatographic behavior of the heteroconjugate is no longer governed primarily by the peptide component; thus, the overall polarity and low hydrophobicity of such heteroconjugates leads to a lack of retention with the TFA mobile phase. Again, because ICPMS detection allows for a quantitative comparison of the phosphorus signal from both samples, the two peak areas were integrated, yielding a value of $1263 \mathrm{cps}$ ( $\sim 95 \mathrm{ppb} \mathrm{P}, \sim 1.2 \mathrm{pmol}$ digested heteroconjugate) for the peak eluting at $1.4 \mathrm{~min}$ and $1181 \mathrm{cps}(\sim 88 \mathrm{ppb} \mathrm{P}, \sim 1.1 \mathrm{pmol}$ undigested heteroconjugate) for the peak eluting at $19.8 \mathrm{~min}$. Overall, analysis of the purified heteroconjugate and various enzymatic digests illustrates that the LC-ICPMS method can be used for the qualitative identification of peptide:oligonucleotide heteroconjugates with high selectivity and provides useful semiquantitative information relating to the abundance of each component in the sample (assuming the number of phosphates per heteroconjugate is known).

\section{Conclusions}

An optimized capillary RP-HPLC-ICPMS method for the selective detection of peptide:oligonucleotide heteroconjugates has been developed. ICPMS enables the selective detection of phosphorus at $\mathrm{m} / \mathrm{z} 31$, which is present in the phosphodiester linkage of the oligonucleotide component in this heteroconjugate. Selective detection of heteroconjugates and, hence, protein:nucleic acid cross-links, is of particular interest owing to the typical low cross-link yields in a background of much more abundant uncross-linked protein and/or nucleic acid. Because we have shown that either TFA-based or HFIP/TEA-based mobile phases, conventionally used for peptide and oligonucleotide RP-HPLC, respectively, are effective at retaining and separating heteroconjugates when coupled with ICPMS, the experimental design and implementation of a capLC-ICPMS method can be adapted based on the anticipated cross-link properties to be analyzed. A variety of enzymatic digestions can be used to generate cross-links where the anticipated peptide component is larger than the oligonucleotide component, thereby allowing for a TFA-based separation of the crosslink, with uncross-linked oligonucleotides eluting in the void volume. Alternatively, digestions can be manipulated to generate cross-links where the anticipated oligonucleotide component is larger than the peptide component, allowing for HFIP/TEA-based separation of the cross-link, with the added benefit that the sensitivity of ICPMS detection is based on the phosphorus response, which will increase with increasing size of the oligonucleotide.
A limitation of the developed method is that LC-ICPMS, alone, cannot be used to identify the peptide or oligonucleotide components nor the site of cross-linking. For those identifications, additional characterization using MALDI- or ESI-MS based methods would be required. Instead, the LCICPMS method developed in this work is envisioned as being a new option for screening protein:nucleic acid crosslink mixtures to identify the number and relative abundance of cross-links that are present. The selectivity of ICPMS can be used to verify the presence of a cross-link (through the ${ }^{31} \mathrm{P}$ response), and because ICPMS is a quantitative technique, the amount of cross-linked material in a sample can be estimated. In addition, while ${ }^{31} \mathrm{P}$ was used here for detection because of the phosphodiester linkages that are present in oligonucleotides, one can envision incorporating other ICPMS-active elements into the cross-linking reagent (e.g., sulfur or platinum) to improve the sensitivity and selectivity for cross-link detection. Furthermore, by using the selective detection of ICPMS, this method could serve as a detector (via split flow) in the first step of the purification of cross-links away from any uncross-linked components, with subsequent identification of the peptide and oligonucleotide components, along with the site of cross-linking, by MALDI- or ESI-based methods. Finally, such a combined approach for protein:nucleic acid cross-link analysis would be equally applicable to either DNA- or RNA-based protein: nucleic acid complexes.

\section{Acknowledgments}

The authors acknowledge financial support for this work by the National Institutes of Health (GM58843 to P.A.L.). The authors thank Jessica Kotha for purifying the heteroconjugate sample used in this work and Agilent Technologies for their continued support and instrumentation.

\section{References}

1. Falkenberg, M., Larsson, N.-G., Gustafsson, C.M.: DNA replication and transcription in mammalian mitochondria. Annu. Rev. Biochem. 76, 679-699 (2007)

2. Sancar, A., Lindsey-Boltz, L.A., Uensal-Kacmaz, K., Linn, S.: Molecular mechanisms of mammalian DNA repair and the DNA damage checkpoints. Annu. Rev. Biochem. 73, 39-85 (2004)

3. Uptain, S.M., Kane, C.M., Chamberlin, M.J.: Basic mechanisms of transcript elongation and its regulation. Annu. Rev. Biochem. 66, 117172 (1997)

4. Staley, J.P., Woolford, J.L.J.: Assembly of ribosomes and spliceosomes: Complex ribonucleoprotein machines. Curr. Opin. Cell Biol. 21, 109118 (2009)

5. Hager, G.L., McNally, J.G., Misteli, T.: Transcription Dynamics. Mol. Cell 35, 741-753 (2009)

6. Jackson, R.J., Hellen, C.U.T., Pestova, T.V.: The Mechanism of eukaryotic translation initiation and principles of its regulation. Nat. Rev. Mol. Cell Biol. 11, 113-127 (2010)

7. Urlaub, H., Hartmuth, K., Kostka, S., Grelle, G., Lührmann, R.: A general approach for identification of RNA-protein cross-linking sites within native human spliceosomal small nuclear ribonucleoproteins (snRNPs). Analysis of RNA-protein contacts in native U1 and U4/U6. U5 snRNPs. J. Biol. Chem. 275, 41458-41468 (2000)

8. Urlaub, H., Hartmuth, K., Lührmann, R.: A two-tracked approach to analyze RNA-protein cross-linking sites in native, nonlabeled small nuclear ribonucleoprotein particles. Methods 26, 170-181 (2002) 
9. Back, J. W., Notenboom, V., de Koning, L. J., Muijsers, A. O., Sixma, T. K., de Koster, C. G., de Jong, L.: Identification of cross-linked peptides for protein interaction studies using mass spectrometry and $18 \mathrm{O}$ labeling. Anal. Chem. 74, 4417-4422 (2002)

10. Back, J. W., de Jong, L., Muijsers, A. O., de Koster, C. G.: Chemical cross-linking and mass spectrometry for protein structural modeling. J. Mol. Biol. 331, 303-313 (2003)

11. Kühn-Hölsken, E., Lenz, C., Sander, B., Lührmann, R., Urlaub, H.: Complete MALDI-TOF MS analysis of cross-linked peptide-RNA oligonucleotides derived from nonlabeled UV-irradiated ribonucleoprotein particles. RNA 11, 1915-1930 (2005)

12. Urlaub, H., Kuhn-Holsken, E., Luhrmann, R.: Analyzing RNA-protein cross-linking sites in unlabeled ribonucleoprotein complexes by mass spectrometry. Methods Mol. Biol. 488, 221-245 (2008)

13. Kramer, K., Hummel, P., Hsiao, H.-H., Luo, X., Wahl, M., Urlaub, H.: Mass spectrometric analysis of proteins cross-linked to 4-thiouracil and 5-bromouracil substituted RNA. Int. J. Mass Spectrom. 304, 184-194 (2011)

14. Campbell, I.D.: Timeline: The march of structural biology. Nat. Rev, Mol. Cell Biol. 3, 377-381 (2002)

15. Christodoulou, J., Larsson, G., Fucini, P., Connell, S.R., Pertinhez, T.A., Hanson, C.L., Redfield, C., Nierhaus, K.H., Robinson, C.V., Schleucher, J., Dobson, C.M.: Heteronuclear NMR investigations of dynamic regions of intact Escherichia coli ribosomes. Proc. Natl. Acad. Sci. U.S.A. 101, 10949-10954 (2004)

16. Frank, J.: Cryo-electron microscopy as an investigative tool: The ribosome as an example. BioEssays 23, 725-732 (2001)

17. Bushnell, D.A., Westover, K.D., Davis, R.E., Kornberg, R.D.: Structural basis of transcription: An RNA polymerase II-TFIIB cocrystal at 4.5 Angstroms. Science (Washington, DC) 303, 983-988 (2004)

18. Jensen, O.N., Kulkarni, S., Aldrich, J.V., Barofsky, D.F.: Characterization of peptide-oligonucleotide heteroconjugates by mass spectrometry. Nucleic Acids Res. 24, 3866-3872 (1996)

19. Sinz, A.: Chemical cross-linking and mass spectrometry to map threedimensional protein structures and protein-protein interactions. Mass Spectrom. Rev. 25, 663-682 (2006)

20. Rusconi, F., Guillonneau, F., Praseuth, D.: Contributions of mass spectrometry in the study of nucleic acid-binding proteins and of nucleic acid-protein interactions. Mass Spectrom. Rev. 21, 305-348 (2002)

21. Richter, F.M., Hsiao, H.-H., Plessmann, U., Urlaub, H.: Enrichment of protein-RNA cross-links from crude UV-irradiated mixtures for MS analysis by on-line chromatography using titanium dioxide columns. Biopolymers 91, 297-309 (2009)

22. Kühn-Hölsken, E., Dybkov, O., Sander, B., Lührmann, R., Urlaub, H.: Improved identification of enriched peptide RNA cross-links from ribonucleoprotein particles (RNPs) by mass spectrometry. Nucleic Acids Res. 35, e95 (2007)

23. Lenz, C., Kühn-Hölsken, E., Urlaub, H.: Detection of protein-RNA cross-links by NanoLC-ESI-MS/MS using precursor ion scanning and multiple reaction monitoring (MRM) experiments. J. Am. Soc. Mass Spectrom. 18, 869-881 (2007)

24. Brock, J.E., Pourshahian, S., Giliberti, J., Limbach, P.A., Janssen, G.R.: Ribosomes bind leaderless mRNA in Escherichia coli through recognition of their 5'-terminal AUG. RNA 14, 2159-2169 (2008)

25. Pourshahian, S., Limbach, P.A.: Application of fractional mass for the identification of peptide-oligonucleotide cross-links by mass spectrometry. J. Mass Spectrom. 43, 1081-1088 (2008)

26. Krivos, K.L., Limbach, P.A.: Sequence analysis of peptide:oligonucleotide heteroconjugates by electron capture dissociation and electron transfer dissociation. J. Am. Soc. Mass Spectrom. 21, 1387-1397 (2010)

27. Urlaub, H., Raker, V.A., Kostka, S., Lührmann, R.: Sm protein-Sm site RNA interactions within the inner ring of the spliceosomal snRNP core structure. EMBO J. 20, 187-196 (2001)

28. Kruger, R., Kubler, D., Pallisse, R., Burkovski, A., Lehmann, W.D.: Protein and proteome phosphorylation stoichiometry analysis by element mass spectrometry. Anal. Chem. 78, 1987-1994 (2006)

29. Navaza, A.P., Encinar, J.R., Sanz-Medel, A.: Absolute and accurate quantification of protein phosphorylation by using an elemental phosphorus standard and element mass spectrometry. Angew. Chem. Int. Ed. 46, 569-571 (2007)

30. Zinn, N., Hahn, B., Pipkorn, R., Schwarzer, D., Lehmann, W.D.: Phosphorus-based absolutely quantified standard peptides for quantitative proteomics. J. Proteome Res. 8, 4870-4875 (2009)

31. Ellis, J., Grimm, R., Clark, J.F., Pyne-Gaithman, G., Wilbur, S., Caruso, J.A.: Studying protein phosphorylation in low MW CSF fractions with capLC-ICPMS and nanoLC-CHIP-ITMS for identification of phosphoproteins. J. Proteome Res. 7, 4736-4742 (2008)

32. Lokits, K.E., Limbach, P.A., Caruso, J.A.: Interfaces for capillary LC with ICPMS detection: A comparison of nebulizers/spray chamber configurations. J. Anal. At. Spectrom. 24, 528-534 (2009)

33. Easter, R.N., Kroning, K.K., Caruso, J.A., Limbach, P.A.: Separation and identification of oligonucleotides by hydrophilic interaction liquid chromatography (HILIC)-inductively coupled plasma mass spectrometry (ICPMS). Analyst 135, 2560-2565 (2010)

34. Hossain, M., Limbach, P.A.: Multiple endonucleases improve MALDIMS signature digestion product detection of bacterial transfer RNAs. Anal Bioanal Chem 394, 1125-1135 (2009)

35. McNaught, A. D., Wilkinson, A.: IUPAC. Compendium of Chemical Terminology, 2nd ed. (the "Gold Book"). Blackwell Scientific Publications, Oxford, (1997) $450 \mathrm{pp}$. 